\title{
Risk factors for post-operative intra-abdominal abscess after laparoscopic appendectomy: a case-control study
}

\author{
J Cho ${ }^{*}$, J Lee, K Sung \\ From ESICM LIVES 2015 \\ Berlin, Germany. 3-7 October 2015
}

\begin{abstract}
Introduction
The risk factors for post-operative intra-abdominal abscess (IAA) formation after laparoscopic appendectomy (LA) remain debatable. Some advocate that a perforated appendicitis or Diabetes Mellitus may increase the incidence of post-operative IAA; however, the existing evidence is insufficient.
\end{abstract}

\section{Objectives}

This study aimed to identify risk factors and non-risk factors for IAA formation in patients receiving LA.

\section{Methods}

From January 2010 to December 2013, all patients who underwent three-port LA and who were histologically diagnosed with appendicitis were included. We classified these patients into two groups according to their development of post-operative IAA and then analyzed the differences between the groups.

\section{Results}

Overall, 1790 patients showed no post-operative complications and were assigned to the non-complication group, whereas 27 patients suffered from IAA postoperatively and were assigned to the IAA group. The incidence of IAA after LA was $1.4 \%$ and the only identified risk factor for IAA was dirty fluid collection in the peritoneal cavity observed during the operation. $(\mathrm{P}<0.001)$ On logistic regression analysis of those patients who demonstrated dirty fluid collection, the non-placement of a peritoneal drain had statistical significance for the development of IAA. $(\mathrm{P}<0.001)$

\section{Conclusions}

In the present study, the presence of dirty fluid collection in the peritoneal cavity rather than the type of appendicitis was demonstrated as a risk factor for the development of post-operative IAA after LA. When such fluid collection is observed, surgeons should consider deploying peritoneal drainage and post-operative antibiotics treatment including anti-anaerobic treatment.

\section{Published: 1 October 2015}

\section{References}

1. Reid Rl, Dobbs BR, Frizelle FA: Risk factors for post-appendicectomy intraabdominal abscess. Aust N Z J Surg 1999, 69:373-4.

2. Ming PC, Yan TY, Tat LH: Risk factors of postoperative infections in adults with complicated appendicitis. Surg Laparosc Endosc Percutan Tech 2009, 19:244-8.

3. Solomkin JS, Mazuski JE, Bradley JS, Rodvold KA, Goldstein EJ, Baron EJ, O' Neill PJ, Chow AW, Dellinger EP, Eachempati SR, Gorbach S, Hilfiker M, May AK, Nathens AB, Sawyer RG, Bartletts JG: Diagnosis and management of complicated intra-abdominal infection in adults and children: guidelines by the Surgical Infection Society and the Infectious Diseases Society of America. Surg Infect 2010, 11:79-109.

4. Petrowsky H, Demartines N, Rousson V, Clavien PA: Evidence-based value of prophylactic drainage in gastrointestinal surgery: a systematic review and meta-analyses. Ann Surg 2004, 240:1074-84.

5. Allemann P, Probst H, Demartines N, Schäfer M: Prevention of infectious complications after laparoscopic appendectomy for complicated acute appendicitis-the role of routine abdominal drainage. Langenbecks Arch Surg 2011, 396:63-8.

doi:10.1186/2197-425X-3-S1-A121

Cite this article as: Cho et al:: Risk factors for post-operative intraabdominal abscess after laparoscopic appendectomy: a case-control study. Intensive Care Medicine Experimental 2015 3(Suppl 1):A121. 